\title{
Textural Evolution and Phase Transformation in Titania Membranes: Part 1.-Unsupported Membranes
}

\author{
Krishnankutty-Nair P. Kumar, Klaas Keizer and Anthonle J. Burggraaf \\ Laboratory for Inorganic Chemistry, Materials Science and Catalysis, Faculty of Chemical \\ Technology, University of Twente, P.O. Box 217, 7500 AE Enschede, The Netherlands
}

\begin{abstract}
Textural evolution in sol-gel derived nanostructured unsupported titania membranes has been studied using differential scanning calorimetry (DSC), differential thermal analysis (DTA), thermal gravimetry (TG), X-ray diffraction (XRD) and $\mathrm{N}_{2}$ adsorption. The anatase-to-rutile phase transformation kinetics were studied using the Avrami model. The precursor gel had a surface area of ca. $165 \mathrm{~m}^{2} \mathrm{~g}^{-1}$, which after heat treatment at $600{ }^{\circ} \mathrm{C}$ for $8 \mathrm{~h}$ reduced to zero. Undoped titania-gel layers transformed to more than $95 \%$ rutile after calcination at $600{ }^{\circ} \mathrm{C}$ for $8 \mathrm{~h}$. The causes of surface-area reduction and pore growth were anatase crystallite growth and the enhanced sintering of rutile during transformation. Lanthanum oxide was identified as a suitable dopant for shifting the transformation temperature to ca. $850^{\circ} \mathrm{C}$. Lanthanum oxide doped titania showed an improved stability of porous texture compared to that of the undoped titania membranes.
\end{abstract}

Keywords: Ceramic membrane; Titania; Phase transformation; Stability; Sol-gel processing

Ceramic membranes are a new class of engineering ceramic systems having great potential for application in hightemperature gas separation and catalysis. They are twodimensional planar structures formed by the regular packing of fine sol-gel-derived ceramic particles (4-100 nm) and/or inorganic polymer clusters. Titania membranes are becoming increasingly important because of their better chemical stability compared to that of the more commonly studied alumina membranes. ${ }^{1}$ However, titania membranes are not stable up to as high temperatures as alumina membranes. Moreover, titania membranes are more prone to microcracking and delamination. There are many papers dealing with the preparation and properties of titania membranes synthesized via the sol-gel route, ${ }^{2,3}$ but very few investigators have focused on the textural evolution of these membranes. ${ }^{2,4}$ In the field of catalysis some work has been done in studying the surface area reduction of bulk titania used for catalyst and catalyst support applications. ${ }^{5}$ In the present paper, a systematic study of the textural evolution of undoped and doped unsupported titania membranes is reported. The major mechanisms of textural instability were identified as anatase crystallite growth and enhanced sintering during the anatase-to-rutile phase transformation. ${ }^{6}$ Based on these findings titania membranes were doped with lanthanum oxide to increase the phasetransformation temperature. In a subsequent paper we discuss the differences between supported and unsupported titania membranes in sintering and in the anatase-to-rutile transformation.

\section{Phase Transformation in the Titania System}

In the titania system, there are three naturally occurring polymorphic forms, namely anatase, rutile and brookite. Among these, brookite was not synthesized in the laboratory until recently. ${ }^{7}$ Zaspalis et $a .^{2}{ }^{2}$ reported that in alkoxidederived gels a small amount of brookite can be detected along with anatase and rutile after calcination. Brookite and anatase are metastable, and transform exothermally to rutile. The transformation is irreversible and occurs over a range of temperatures. The free energy of rutile in the anatase-rutile system must be lower, at least above $400{ }^{\circ} \mathrm{C}$, since the transformation proceeds at that temperature in the presence of an alkali flux. ${ }^{8}$
The temperature at which anatase completely transforms to rutile ranges from 400 to $1200^{\circ} \mathrm{C} .^{2.7-20}$ Based on XRD studies Zaspalis et al. ${ }^{2}$ detected $100 \%$ rutile in alkoxidederived samples after calcination at $600{ }^{\circ} \mathrm{C}$ for $3 \mathrm{~h}$. Knoll and Kühnhold ${ }^{13}$ reported a transformation temperature of $655^{\circ} \mathrm{C}$ based on DTA. Czanderna et al ${ }^{14}$ reported that a sample of spectroscopically pure titanium dioxide consists of $100 \%$ rutile after calcination at $728^{\circ} \mathrm{C}$ for $4 \mathrm{~h}$. They prepared the samples via oxidation of titanium metal in an ammoniacal solution containing hydrogen peroxide. They also found that there is no appreciable anatase-rutile conversion below $610{ }^{\circ} \mathrm{C}$ irrespective of the calcination time. Balachandran and Eror ${ }^{11}$ reported $750{ }^{\circ} \mathrm{C}$ for the anatase-to-rutile transformation temperature of titanium dioxide prepared by the thermal decomposition of tetraisopropyl titanate. Iida and Ozaki ${ }^{12}$ found $100 \%$ anatase in samples, derived from the decomposition of ammonium titanium sulfate held at $800{ }^{\circ} \mathrm{C}$ for $3 \mathrm{~h}$. The temperature at which anatase completely transforms to rutile depends on many factors such as the impurities present in anatase, ${ }^{18}$ the method of preparation, ${ }^{12}$ the oxygento-metal coordination in the precursor, ${ }^{19}$ and the oxygen-tometal bond length in the precursor gel. ${ }^{21}$ Some investigators believe that it depends on the texture and primary particle size of anatase. ${ }^{9,12}$ It will be shown in the subsequent paper that in the case of supported titania membranes the support constraint plays an important role in determining the sintering and phase transformation behaviour.

\section{Experimental}

\section{Preparation of the Sol and the Membranes}

The precursor sols for undoped titania and the lanthanadoped titania membranes were prepared by hydrolysing titanium isopropoxide with water. A step-by-step synthesis procedure is given in Fig. 1. The hydrolysis reaction was carried out by the dropwise addition of an alcoholic solution of titanium isopropoxide $(0.22 \mathrm{~mol}$ in $400 \mathrm{ml}$ of isopropyl alcohol $900 \mathrm{ml}$ ). The solution was stirred vigorously using a mechanical stirrer. The titanium oxyhydroxide precipitate obtained after hydrolysis was filtered and washed to remove all the isopropyl alcohol present. The washed precipitate was transferred to a beaker and redispersed by adding watercontaining nitric acid $\left(\mathrm{H}^{+} / \mathrm{Ti}^{4+}=0.5\right)$. The dispersion process 


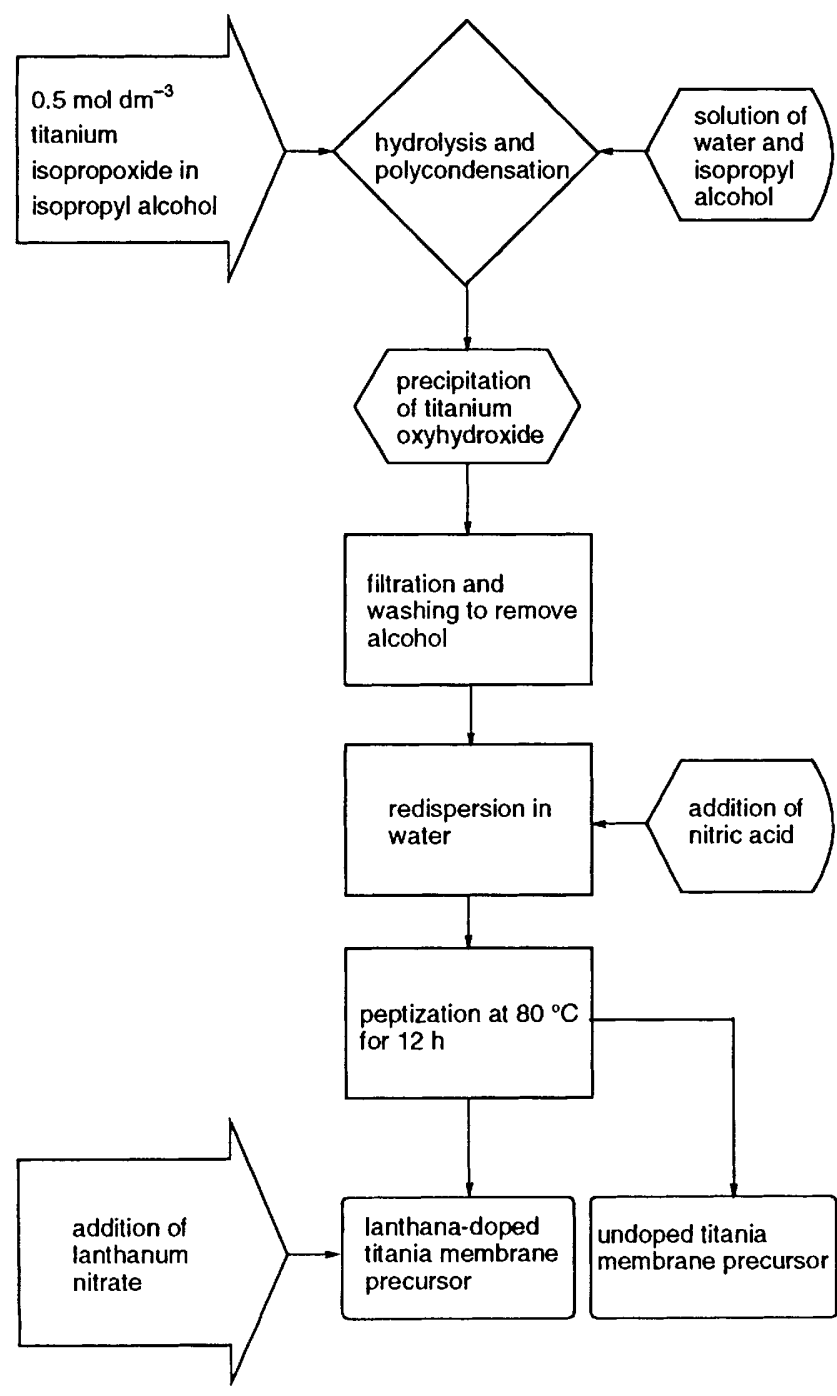

Fig. 1 Flow chart giving the step-by-step synthesis procedure of undoped titania and lanthana-doped titania membrane precursor sols

was accelerated by mechanical stirring. The slurry was peptized at $80{ }^{\circ} \mathrm{C}$ by refluxing for $12 \mathrm{~h}$. This treatment yielded a translucent sol with a pH of ca.2. The precursor sol for lanthana-doped membranes was prepared by adding lanthanum nitrate crystals to the peptized sol to obtain a composition of $\mathrm{Ti}_{0.925} \mathrm{La}_{0.075} \mathrm{O}_{2}$. Care should be taken to stir vigorously to avoid concentration gradients of the dopants, which may destabilize the sol. Small quantities of lanthanum nitrate will not destabilize the sol if the mixture is carefully stirred during addition. Unsupported titania membranes were prepared by pouring appropriate amounts of the sol into a glass petri dish. The sol was dried at controlled temperature and relative humidity to produce unsupported membranes $7-40 \mu \mathrm{m}$ thick. All the membranes studied in the present work were dried at $40{ }^{\circ} \mathrm{C}$ and $60 \%$ relative humidity in a Heraeus Vötsch climate chamber (VTRK 300), with an air flow rate of $0.5 \mathrm{~m} \mathrm{~s}^{-1}$. Wind screens were used to ensure laminar flow around the drying membrane layers. The membranes used in this study were in the thickness range $12-15 \mu \mathrm{m}$ after drying.

\section{Thermal Analysis}

The dried gel was subjected to thermal analysis in a Stanton Redcroft DSC and a Polymer Lab. Thermal Science DTA and TG. The DTA and TG measurements were performed with a heating rate of $10{ }^{\circ} \mathrm{C} \mathrm{min}{ }^{-1}$ in flowing air $(20 \mathrm{ml}$ $\min ^{-1}$ ). DSC measurements for kinetic studies were performed at heating rates in the range $5-20{ }^{\circ} \mathrm{C} \mathrm{min}{ }^{-1}$. All the thermal analyses were carried out in air using alumina sample cups with $\alpha$-alumina as the reference material. The sample weight was kept at $40 \pm 2 \mathrm{mg}$. Thermal behaviour below $500{ }^{\circ} \mathrm{C}$ was studied using a high-sensitivity low-temperature cell for the DSC instrument with an aluminium sample cup.

\section{X-Ray Diffraction}

X-Ray powder diffraction measurements were carried out using a Philips $\mathrm{PW} 1710$ diffractometer with $\mathrm{Cu}-\mathrm{K} \alpha$ radiation. In order to obtain highly accurate data only the step-scan technique was used. The step-scans were performed with a step size of $0.015^{\circ}(2 \theta)$, the counting time at each step was $10 \mathrm{~s}$ and the scanning range was from 23 to $46^{\circ}(2 \theta)$. The crystallite size and the relative amounts of anatase and rutile phase present were calculated from the (101) reflection of anatase and the (110) reflection of rutile. To measure accurately the integrated intensity and the width at half maximum, a pattern-fitting technique was applied. ${ }^{22}$ To carry out the fit the Marquart non-linear least-squares algorithm was used. ${ }^{23}$ The instrument- and wavelength-related broadenings were corrected by assuming a Cauchy relationship. ${ }^{24}$ The Cauchy approximation accounts only for size broadening and the presence of strain is neglected, but for comparison purposes it is a good approximation. The crystallite sizes of anatase and rutile phases were calculated using the Scherrer relationship:

$$
D_{h k l}=K \lambda /\left(B_{h k l} \cos \theta\right)
$$

where $B_{h k l}$ is the width of the peak at half maximum and $\lambda$ is the wavelength of $\mathrm{Cu}-\mathrm{K} \alpha$ radiation. The value of $K$ varies from 0.9 to 1.4 depending on many factors including the shape of the primary crystallite. In this study, a value of 1.38 is assumed for $K$, which accounts for the deviation from pure Cauchy behaviour.

The fraction of rutile present in the membranes after various heat treatments were calculated using the equation: ${ }^{25}$

$$
W_{\mathbf{R}}=1 /\left[1+0.8\left(I_{\mathrm{A}} / I_{\mathrm{R}}\right)\right]
$$

$W_{\mathrm{R}}$ is the weight fraction of rutile, and $I_{\mathrm{A}}$ and $I_{\mathrm{R}}$ are the X-ray integrated intensities of the (101) reflection of anatase and the (110) reflection of rutile respectively. The integrated intensity was calculated after correcting for the effects of instrumentand wavelength-related broadening.

\section{Calcination Procedure}

Two different calcination procedures were followed. In the first, the dried membranes were heat-treated at different temperatures from 200 to $800{ }^{\circ} \mathrm{C}$ for $8 \mathrm{~h}$ with a heating rate of $100{ }^{\circ} \mathrm{C} \mathrm{h}^{-1}$ in static air. After soaking, the samples were furnace cooled to room temperature. The second procedure, for kinetic studies, was carried out by introducing the samples into a furnace maintained at the specified temperature. After thermal soaking the samples were quenched by removing them from the furnace. Details are given elsewhere. ${ }^{26}$

\section{Physical Adsorption Measurements}

$\mathrm{N}_{2}$ adsorption/desorption measurements were carried out at liquid-nitrogen temperature in a Micromeritics ASAP 2400 system. All the samples were degassed at $90{ }^{\circ} \mathrm{C}$ prior to the actual adsorption/desorption measurements. Among the samples studied only the dried $\left(40{ }^{\circ} \mathrm{C}\right.$ and $\left.60 \% \mathrm{RH}\right)$ gel 
showed complete microporosity, which will be discussed in the section on textural evolution and sintering. No correction was applied to eliminate the effect of microporosity because all the samples heat treated at $300{ }^{\circ} \mathrm{C}$ and above showed very little or no microporosity. The BET constant was in the range $100-200$ and is discussed again in the section on textural evolution and sintering. The pore diameter, after correcting for the adsorbed layer, was calculated from the desorption branch of the isotherm unless stated otherwise.

\section{Electron Microscopy}

Titania membranes were subjected to a high-resolution fieldemission scanning electron microscopic (FE-SEM) study using a Hitachi S-900 SEM. Because of the high emission intensity in the field emission, there was sufficient current available to allow excellent resolution with good signal-to-noise ratio. The specimens were made conducting by coating with platinum. Magnifications ranged from 100000 to 200000 .

\section{Results and Discussion}

\section{Thermal Behaviour and Phase Transformation}

The XRD pattern of the as-dried titania gel layer is given in Fig. 2. It is interesting to note that the as-prepared gel is already crystalline. All the peaks are very broad, owing to the very fine primary crystallites, though possible additional causes of line broadening are defects and residual hydroxy groups in the lattice. The crystallite size calculated using eqn. (1) was ca. $5 \mathrm{~nm}$. All the reflections in the XRD pattern of the gel correspond to anatase.

Fig. 3(a) (b) illustrate the DSC traces, with a heating rate of $10{ }^{\circ} \mathrm{C}$, that were recorded with both low- and high-

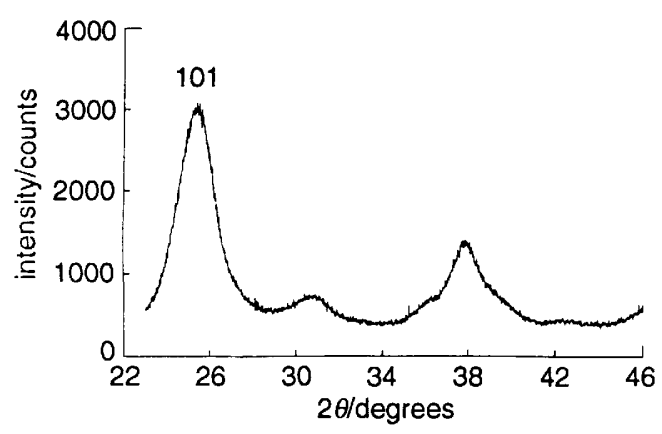

Fig. $2 \mathrm{X}$-Ray diffraction pattern of the titania gel layer dried at $40{ }^{\circ} \mathrm{C}$ in $60 \%$ relative humidity for $24 \mathrm{~h}$

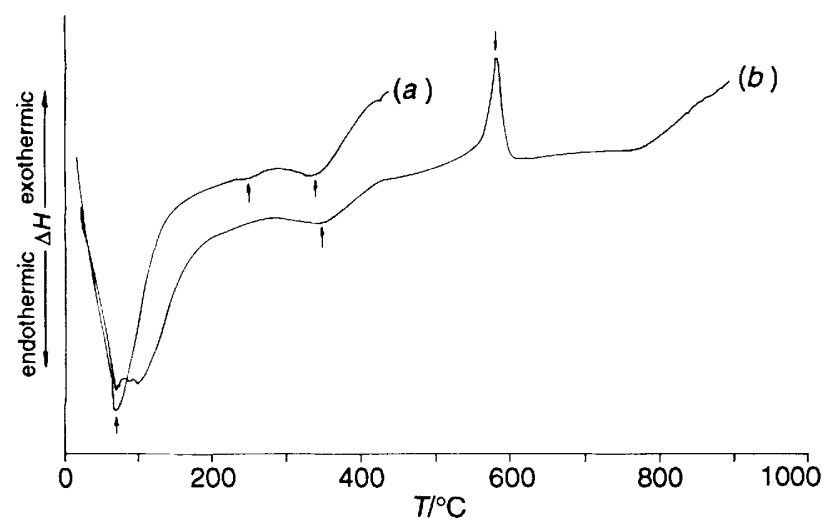

Fig. 3 DSC trace of unsupported titania membranes performed using (a) high-sensitivity low-temperature cell and (b) high-temperature cell. $y$-axis is in arbitrary units temperature cells, respectively, of unsupported membranes. There are two peaks in the low-temperature region of the high-temperature DSC [curve (b)] and in the low-temperature high-sensitivity DSC [curve (a)]. The peak at ca. $95^{\circ} \mathrm{C}$, represents the removal of the physically adsorbed water that is present in the pores. The peak at $c a .350{ }^{\circ} \mathrm{C}$ represents the dehydroxylation reaction and the decomposition of nitrates in the peptized gel. There is an additional, but small, peak at ca. $250^{\circ} \mathrm{C}$, which is discussed along with the DTA results. In the high-temperature region [curve $(b)$ ] we clearly see a sharp exothermic peak at $580{ }^{\circ} \mathrm{C}$, which is due to the anatase-torutile transformation and the recrystallization reaction. In this situation, recrystallization and phase transformation proceed simultaneously. Hence, the heat released during phase transformation stimulates the recrystallization process. ${ }^{10}$ The total heat associated with the DSC exotherm [Fig. 3(b)] was calculated to be $11 \pm 2 \mathrm{~kJ} \mathrm{~mol}^{-1}$. From the literature it can be noted that the enthalpy of the anatase-rutile transformation is only $6 \mathrm{~kJ} \mathrm{~mol}^{-1}$. Therefore, in the present case the excess $5 \mathrm{~kJ} \mathrm{~mol}^{-1}$ is the heat released by the grain growth. The observation of excess heat released due to grain growth is in qualitative agreement with the findings of Sheinkman et al. ${ }^{10}$ Again, note that the anatase-to-rutile transformation is a metastable-to-stable transformation and therefore there is no unique phase transformation temperature as in the case of equilibrium reversible transformations. The peak temperature obtained from DSC is simply the temperature at which the transformation rate is the highest and it depends on the heating rate. A DSC transformation temperature of $580^{\circ} \mathrm{C}$ does not mean that rutile is not present in samples heattreated below this temperature. In fact, the titania samples studied in the present work already start transforming to rutile around $400{ }^{\circ} \mathrm{C}$, and after calcination at $600{ }^{\circ} \mathrm{C}$ for $8 \mathrm{~h}$ it transforms to $>95 \mathrm{wt} . \%$ rutile. In this paper the transformation temperature is defined as that temperature above which the sample contains more than $95 \mathrm{wt} \% \%$ rutile for a given heating rate.

DTA, TG and DTG traces of titania gel layers are shown in Fig. 4. In the TG trace, there are two weight-loss regions, the first with a midpoint at ca. $95^{\circ} \mathrm{C}$, corresponding to the loss of water from the porous gel network, accounts for more than $50 \%$ of the weight loss. The major part of the second region, centred at $c a .300{ }^{\circ} \mathrm{C}$, represents the removal of the attached hydroxy groups. After $c a .400{ }^{\circ} \mathrm{C}$, there is no further weight loss, as indicated by the plateau in the TG. This observation is in agreement with the DSC results explained above and with the DTA and DTG results which are discussed

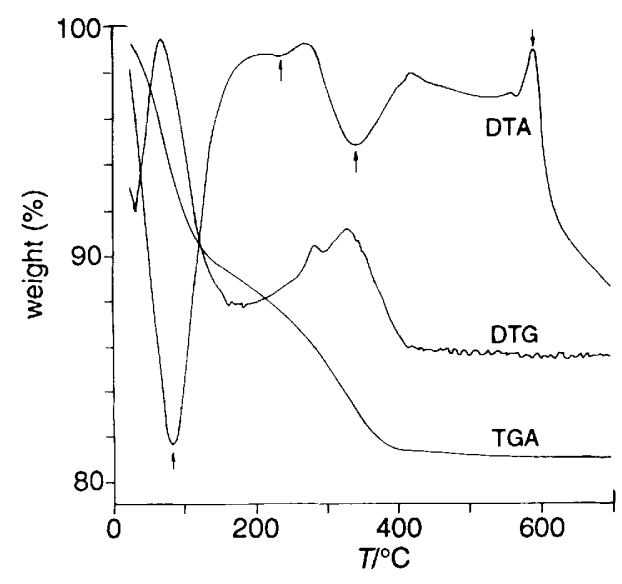

Fig. 4 DTA, TG and DTG traces of unsupported titania membranes. $y$-axis represent the weight percentage and $x$-axis represents the temperature 
below. In the DTA trace, there are three dips on the lowtemperature side. Those at $\mathrm{ca} .95$ and $350{ }^{\circ} \mathrm{C}$ represent the same processes as discussed above for DSC and TG. A new dip at $c a .250{ }^{\circ} \mathrm{C}$, which is only present in the high-sensitivity DSC [see Fig. 3(a)], may be due to the water loss from very small pores $(<2 \mathrm{~nm})$. The three peaks in the DTG (derivative of TG) are consistent with DTA and DTG.

The XRD pattern of the membranes heated at different temperatures are given in Fig. 5. The peaks marked A represent anatase and the ones marked $\mathrm{R}$ represent rutile. At $300{ }^{\circ} \mathrm{C}$ the membrane is completely anatase and the peaks corresponding to rutile start appearing at $450{ }^{\circ} \mathrm{C}$. At $600{ }^{\circ} \mathrm{C}$ more than $95 \%$ has transformed to rutile.

\section{Phase Transformation Kinetics}

The anatase-to-rutile transformation is a metastable-to-stable (irreversible) type and at all temperatures, the free energy of the rutile phase is expected to be lower than that of anatase. The amount of rutile present in the membranes heated at specified temperatures for different times was calculated from the integrated intensity of the (101) peak of anatase and the (110) peak of rutile according to the eqn. (2). Fig. 6 gives the fraction of rutile present in the membranes heated at 390,430 and $470{ }^{\circ} \mathrm{C}$ for different times. All the calcinations for phasetransformation kinetic studies were carried out by directly introducing the samples into the preheated furnace for specified periods. The transformation curves (Fig. 6) have an S-shape representing the normal nucleation growth type of behaviour. ${ }^{27}$

The data presented in Fig. 6 can conveniently be reduced

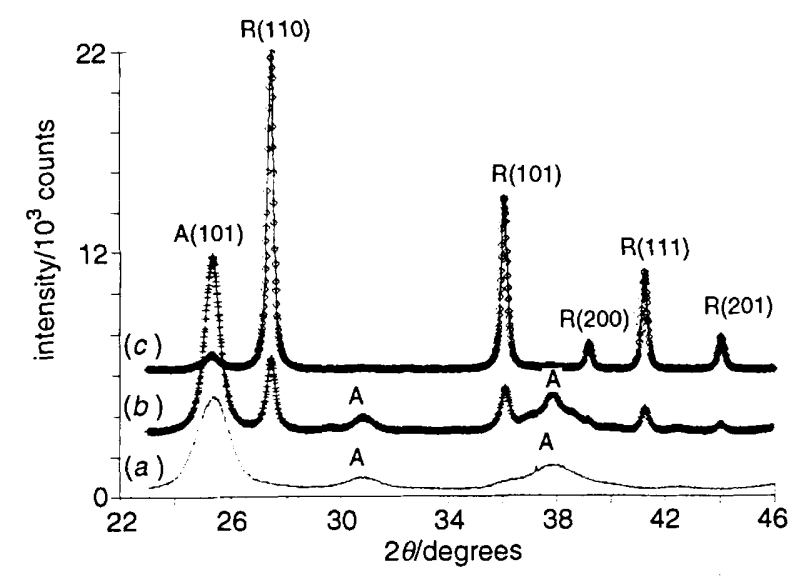

Fig. 5 X-Ray diffraction pattern of unsupported titania membranes heated at $(a) 300,(b) 450$ and $(c) 600{ }^{\circ} \mathrm{C}$ for $8 \mathrm{~h}$. The peaks marked $\mathrm{A}$ and $\mathrm{R}$ represent the anatase and the rutile phases.

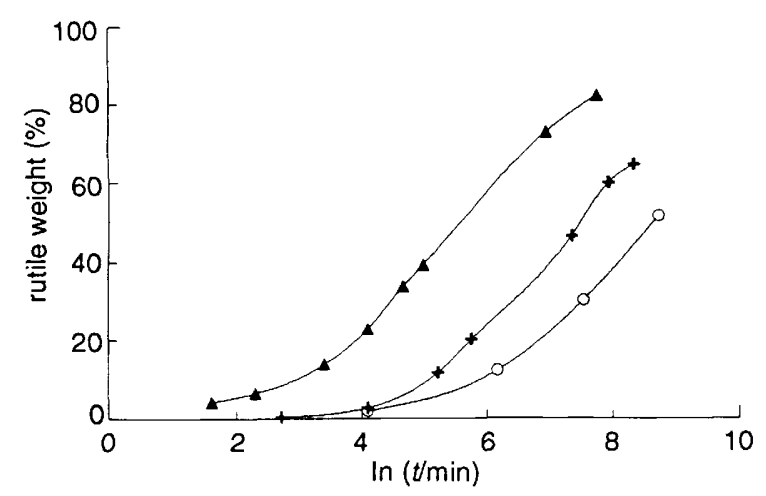

Fig. 6 Fraction of rutile present in the undoped titania when heattreated at $(\bigcirc) 390,(+) 430$ and $(\Delta) 470{ }^{\circ} \mathrm{C}$ for different soaking periods using the well known Avrami equation: ${ }^{27}$

$$
\ln \{\ln [1 /(1-y)]\}=n \ln t+n \ln k
$$

where $y$ is the fraction transformed in time $t, n$ is an exponent, the value of which depends on the type of transformation reaction, and $k$ is the rate constant.

Values of $k$ and $n$ for each temperature are given in Table 1. The average value of $n$ is $c a$. 0.66 . This is clear evidence of transformation reactions in which the nucleation sites are either dislocations or vacancies. ${ }^{27}$ This is in good agreement with the reported mechanism of the anatase-to-rutile transformation, where vacancies are assumed to play an important role. ${ }^{9,12,18,28}$ The activation energy for the rate constant $k$ was calculated to be $147 \mathrm{~kJ} \mathrm{~mol}^{-1}$. This is $c a .1 / 3$ of the value reported in the literature ${ }^{28}$ for titania undergoing complete transformation above $800^{\circ} \mathrm{C}$.

The DTA transformation peak is at ca. $580{ }^{\circ} \mathrm{C}$ (heating rate of $10{ }^{\circ} \mathrm{C} \mathrm{min}^{-1}$ ) for the titania membranes discussed here, whereas in the literature the reported transformation temperatures range from 700 to $1100^{\circ} \mathrm{C}$. Iida and Ozaki ${ }^{12}$ have studied the effect of the method of preparation on the transformation temperature. They concluded that the transformation temperature depends on the structure, coordination and crystallinity of the oxyhydroxide precursor. Zaspalis et al. $^{2}$ have shown that the presence of sulfate ions increases the anatase-to-rutile transformation temperature of alkoxidederived gels and membranes. In general, the transformation temperature should depend upon the chemical and physical properties of the oxyhydroxide that is formed after hydrolysis. In the present case, the oxyhydroxide formed by the hydrolysis of titanium isopropoxide is probably different from the one reported by Iida and Ozaki, ${ }^{12}$ because of the difference in the preparation routes. The anatase-rutile transformation involves an overall contraction of the oxygen structure, as indicated by a volume shrinkage of $c a .8 \%$, and a co-operative movement of ions. Therefore, the removal of oxygen ions might be expected to accelerate the transformation. ${ }^{9}$ The BET surface area of titania membranes was found to be $150 \mathrm{~m}^{2}$ $\mathrm{g}^{-1}$ after $24 \mathrm{~h}$ at $300^{\circ} \mathrm{C}$. A material with a high surface area is expected to show a lower transformation temperature because of its high defect concentration. This may again be due to the fact that these materials may have a relatively high oxygen vacancy concentration at the surface. Moreover, a shorter diffusion distance for the vacancies will favour the transformation rate. Therefore it is reasonable to suppose that high-surface-area gel-derived materials should have a lower transformation temperature. Moreover, nucleation on defects is probably much easier in the case of gel-derived materials because of the disordered structure of the primary crystallites which is evident from the very broad XRD pattern given in Fig. 2. Another possible reason for the lower transformation temperature may be the possible presence of organic matter in the gel. Ocana et al. have observed the presence of rutile below $400{ }^{\circ} \mathrm{C}$ in anatase-derived titania and they have attributed this to the presence of organics which can act as nucleation sites present in the gel. ${ }^{29}$

Table 1 Kinetic parameters $n$ and $k$ calculated from the Avrami model

\begin{tabular}{lcc}
\hline$T{ }^{\circ} \mathrm{C}$ & $n$ & $k$ \\
\hline 390 & 0.674 & $1.05 \times 10^{-4}$ \\
430 & 0.672 & $2.89 \times 10^{-4}$ \\
470 & 0.641 & $1.88 \times 10^{-3}$ \\
average & 0.6623 & - \\
\hline
\end{tabular}




\section{Textural Evolution and Sintering}

Fig. 7 gives the $\mathrm{N}_{2}$ adsorption-desorption isotherms of the gel and the membranes heated at 300 and $450{ }^{\circ} \mathrm{C}$ for $8 \mathrm{~h}$. The isotherm corresponding to the gel is a typical type $\mathrm{I}$ isotherm (BDDT classification ${ }^{30,31}$ ) indicating that it is completely microporous (pore diameter $<2 \mathrm{~nm}$; IUPAC classification). The absence of any type of hysteresis is a perfect indication of the absence of mesoporosity (pores of $2-50 \mathrm{~nm}^{30-32}$ ). After the gel layer had been heated at $300{ }^{\circ} \mathrm{C}$ the isotherm changed from pure type I to a combination of type I and IV. ${ }^{30-32}$ At this stage more than $95 \%$ of the pores have grown to the mesoporous range. The shape of the hysteresis is a combination of types $\mathrm{C}$ and $\mathrm{E} .^{30}$ In type $\mathrm{C}$, the adsorption branch is steep at intermediate relative pressures, and the desorption branch is sloping; whereas, in type $E$ the adsorption branch has a sloping character, and the desorption branch is steep at intermediate relative pressures. Both C- and E-type hysteresis loops are common for porous systems containing a heterogeneous distribution of cylindrical capillaries. In the membrane heated at $300^{\circ} \mathrm{C}$, both adsorption and desorption branches are sloping at intermediate relative pressures indicating that the dimensions which are responsible for both the adsorption (type E) and desorption (type C) branches are heterogeneously distributed. ${ }^{30}$ This means that the pore entrance and the bulk of the pore do not have a sharp size distribution.

After the samples had been heated at $450{ }^{\circ} \mathrm{C}$ the pores in the membranes grew further as indicated by the shift in the relative pressure corresponding to the closure of the hysteresis loop compared to the membrane heated at $300{ }^{\circ} \mathrm{C}$. The shape of the hysteresis loop changes from a combination of $\mathrm{E}$ and $\mathrm{C}$ types at $300{ }^{\circ} \mathrm{C}$ to $\mathrm{E}$ type at $450{ }^{\circ} \mathrm{C} \cdot{ }^{31} \mathrm{E}$-type hysteresis is associated with spherical pores and voids created by the close packing of spherical particles or with 'ink-bottle' type pores. When sintering proceeds further the spherical interstitial cavities will gradually become cylindrical at the beginning of the second stage of sintering. This may be the reason why we have a combination of $\mathbf{E}$ - and A-type hysteresis on further heat treatment above $450{ }^{\circ} \mathrm{C}$ (not shown in the figure). A-type hysteresis is typical for cylindrical pores.

Surface areas and pore diameters for a membrane heated at different temperatures are given in Fig. 8. In the dried gel state the BET surface area is $c a .165 \mathrm{~m}^{2} \mathrm{~g}^{-1}$. In general the surface area for materials containing micropores, calculated using the BET model, is overestimated owing to the presence of micropores. In the present case the calculated surface area of the dried gel is reasonable compared with heat-treated samples with no or small amounts of microporosity. Moreover, the BET constant is in the range 100-200 indicating

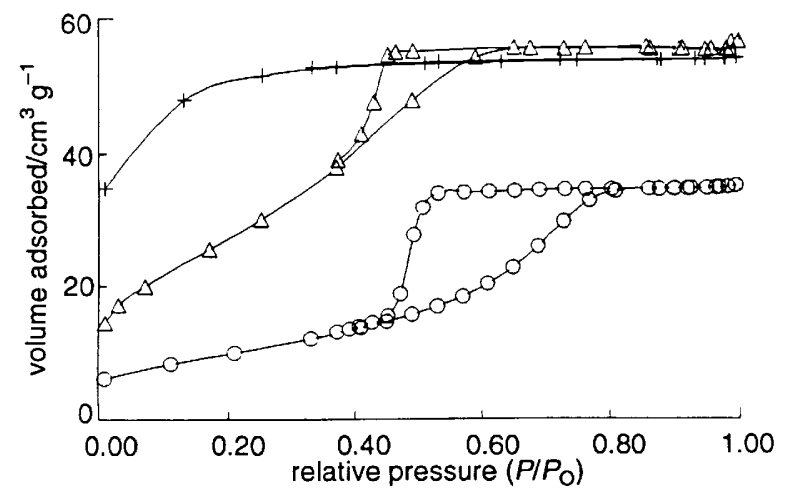

Fig. 7 Nitrogen adsorption/desorption isotherms of the undoped unsupported titania membranes in the gel state $(+)$ and heated at $300(\triangle)$ and $450^{\circ} \mathrm{C}(\bigcirc)$

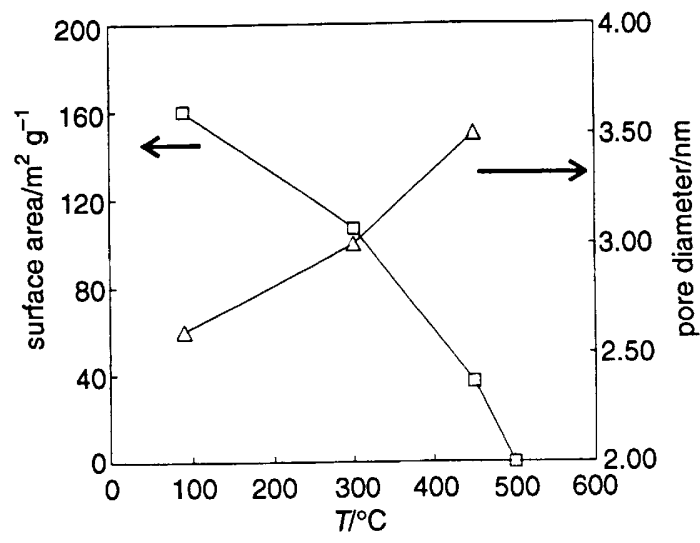

Fig. 8 Effect of calcination temperature on BET surface area and pore diameter (calculated from the desorption branch of the isotherm) of unsupported titania membranes

that the BET surface area is not an overestimate. ${ }^{30}$ BET surface-area values of microporous materials with BET constants of the order of $10^{4}$ or more are exaggerated values and need to be corrected. On heat treatment at $450{ }^{\circ} \mathrm{C}$ the surface area reduces to $c a .30 \mathrm{~m}^{2} \mathrm{~g}^{-1}$. After treatment at $500^{\circ} \mathrm{C}$ it is immeasurably low. The initial pore diameter in the gel state is less than $2 \mathrm{~nm}$ and it grows to $c a .3 .5 \mathrm{~nm}$ when heated at $450{ }^{\circ} \mathrm{C}$ for $8 \mathrm{~h}$. In Table 2 a summary of pore diameters and porosities of unsupported titania membranes heated at several temperatures for $8 \mathrm{~h}$ is given.

Membranes were subjected to isothermal heat treatments at various temperatures to study the textural evolution with time. Fig. 9 presents $\mathrm{N}_{2}$ adsorption-desorption isotherms of membranes heated at $390{ }^{\circ} \mathrm{C}$ for different times from $5 \mathrm{~min}$ to $103 \mathrm{~h}$. The $5 \mathrm{~min}$ sample shows a combination of type I and type IV behaviour with a small hysteresis loop. A difference between the samples calcined at different temperatures is the shift in the point at which the desorption branch starts deviating from the adsorption branch. With increasing temperature the beginning of hysteresis shifts towards higher

Table 2 Pore diameter and porosities of unsupported titania membranes, calculated from the desorption branch of an $\mathrm{N}_{2}$ adsorption/ desorption curve

\begin{tabular}{lcc}
\hline $\begin{array}{l}\text { calcination } \\
\text { temperature } /{ }^{\circ} \mathrm{C}\end{array}$ & pore diameter $/ \mathrm{nm}$ & $\%$ porosity \\
\hline 40 (gel) & $<2$ & 30 \\
300 & 2.8 & 25 \\
450 & 3.5 & 15 \\
\hline
\end{tabular}

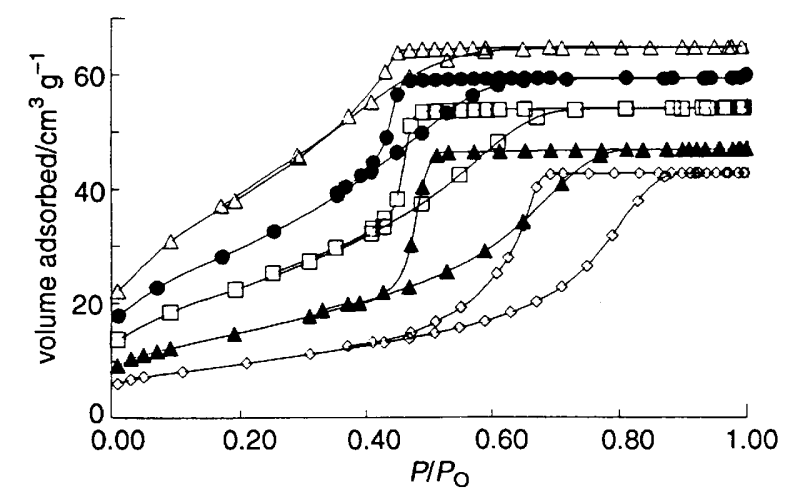

Fig. 9 Nitrogen adsorption/desorption isotherms of unsupported titania membranes heated at $390^{\circ} \mathrm{C}$ for: $(\triangle) 5,(\bullet) 75,(\square) 480,(\Delta)$ 1885 and $(\diamond) 6155 \mathrm{~min}$. 
$P / P_{0}$, indicating pore growth. This is made clear in Fig. 10 , where the mean pore size, calculated from both adsorption and desorption branches, increases with increasing calcination time. The shape of the hysteresis loop changes from a combination of $\mathrm{E}$ and $\mathrm{C}$, then to $\mathrm{E}$ and finally to a combination of $\mathrm{C}$ and $\mathrm{E} .{ }^{30}$ The relative pressure, $\left(P / P_{\mathrm{e}}\right)$, at which the straight line portion of the desorption branch bends down to join the adsorption branch is a characteristic of the porous texture of the system. The sharpness of the transition at $\left(P / P_{e}\right)$ is different for different calcination times. An abrupt transition indicates a sharply peaked distribution of neck radii. ${ }^{33}$ The sharpness of transition at $\left(P / P_{\mathrm{e}}\right)$ increases initially with calcination time and after $c a .31 .5 \mathrm{~h}$ it again becomes less sharp. This means that the distribution of neck radii becomes narrow in the intermediate stage and becomes randomly distributed again for increased heating times. The pore morphology is changing from spherical to cylindrical and back to a combination of cylindrical and spherical.

\section{Isothermal Surface Area Reduction}

The reduction in surface area at 300,350 and $390{ }^{\circ} \mathrm{C}$ for different heating times is given in Fig. 11. These temperatures were selected because the membranes heat treated at $300^{\circ} \mathrm{C}$ and above do not show the presence of microporosity. The curves for 350 and $390{ }^{\circ} \mathrm{C}$ follow the same pattern, whereas the curve corresponding to $300{ }^{\circ} \mathrm{C}$ has an initial steep portion indicating drastic reduction in surface area. This may be due to the enhanced sintering caused by the surface hydroxy groups present at $300^{\circ} \mathrm{C} \cdot{ }^{34,35}$ Sintering enhancement through activated transport by a hydroxy bridging mechanism has been confirmed by other investigators. ${ }^{34,35}$ In the case of gelderived titania, $\mathrm{OH}$ groups are present at least up to $c a$. $300{ }^{\circ} \mathrm{C}$, as shown in the TG given in Fig. 4. The sample heated

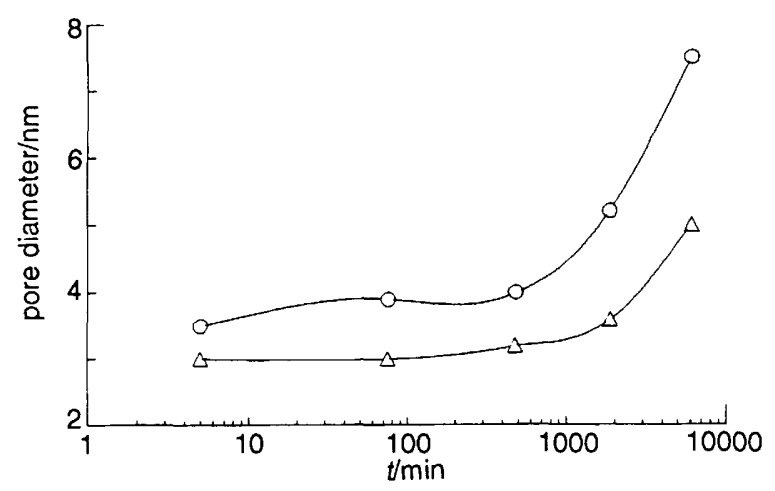

Fig. 10 Pore growth of unsupported titania membrane heated at $390^{\circ} \mathrm{C}$ for different times. Pore diameters were calculated from both the adsorption $(O)$ and desorption $(\triangle)$ branches of the isotherm

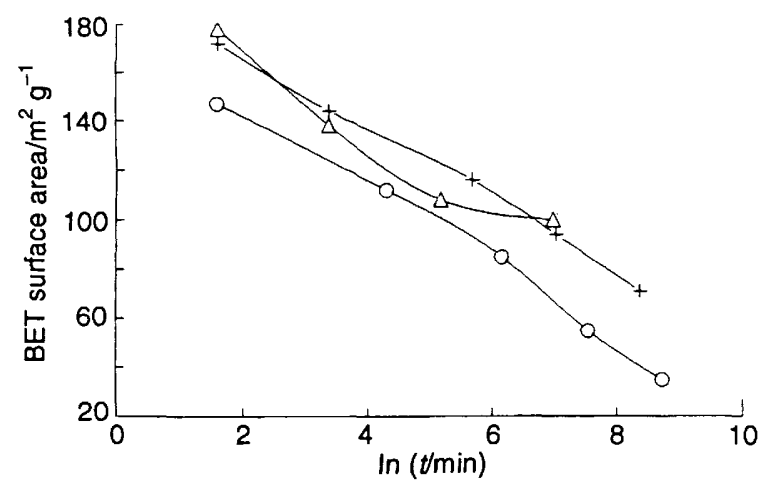

Fig. 11 Effect of calcination temperature and time on surface area of unsupported titania membranes: $(\triangle) 300,(+) 350,(O) 390^{\circ} \mathrm{C}$. at $350{ }^{\circ} \mathrm{C}$ loses residual water much faster than the $300{ }^{\circ} \mathrm{C}$ sample because of the higher calcination temperature. The sample heated at $300^{\circ} \mathrm{C}$ had a lower surface area at intermediate times compared with those heated at $350^{\circ} \mathrm{C}$. This suggests that at and above $350^{\circ} \mathrm{C}$ the contribution of residual hydroxy groups to sintering is small.

\section{Influence of Phase Transformation on Surface Area Reduction}

Fig. 12 gives the surface area of membranes heated at $390^{\circ} \mathrm{C}$ for different times $(5 \mathrm{~min}, 1 \mathrm{~h}, 8 \mathrm{~h}, 30 \mathrm{~h}$ and $100 \mathrm{~h})$. On the $x$ axis the fraction of rutile present in the membranes [calculated using eqn. (2)] is given instead of soaking time. It should be remembered that the fraction of rutile present is a function of time [eqn. (5)]. The open and closed triangles represent the crystallite size of the anatase and rutile crystallites, respectively. These were calculated using eqn. (1). It is clearly seen that there is an appreciable size difference between rutile and anatase crystallites present in the same sample. This indicates that the rutile phase grows rapidly to large dimensions during the phase transformation. The growth is very intense as can be seen from the energy associated with the process $\left.\left(5 \mathrm{~kJ} \mathrm{~mol}^{-1}\right)\right)^{6,10}$ During the transformation the growth rate of both anatase and rutile seems to be the same. This can be seen from Fig. 12 by comparing the slopes of the fraction transformed (time of calcination) versus crystallite growth curves corresponding to anatase and rutile.

The total energy released during the process of phase transformation and the grain growth was found to be $c a$. $11 \mathrm{~kJ} \mathrm{~mol}^{-1}$. An estimate of the rise in temperature during the above process can be made by assuming the specific heat capacity of titania at constant pressure $\left(C_{p}\right)$ to be $c a$. $60 \mathrm{~J} \mathrm{~mol}^{-1} \mathrm{~K}^{-1.36}$ The temperature rise per mole of titania transformed is found to be $c a .180^{\circ} \mathrm{C}$ assuming adiabatic conditions $\left(\Delta T=Q / C_{p}=11000 / 60{ }^{\circ} \mathrm{C}=180^{\circ} \mathrm{C}\right)$. The assumption of adiabatic conditions is reasonable because the thermal conductivity of rutile is rather small $\left(3-4 \mathrm{~J} \mathrm{~s}^{-1} \mathrm{~K}^{-1} \mathrm{~m}^{-1}\right)$ and individual transformation regions are also small $(<100 \mathrm{~nm}$ in size). The whole transformation is complete in a few hours and the actual duration depends on the temperature of calcination. In any given region in the sample the transformation is instantaneous and therefore we can expect a localized temperature rise of $c a .150-200{ }^{\circ} \mathrm{C}$.

There are two remarkable observations from the textural evolution studies reported here. The first one is that it was not possible to make a dense membrane with anatase as the major phase. The second observation is that it was not

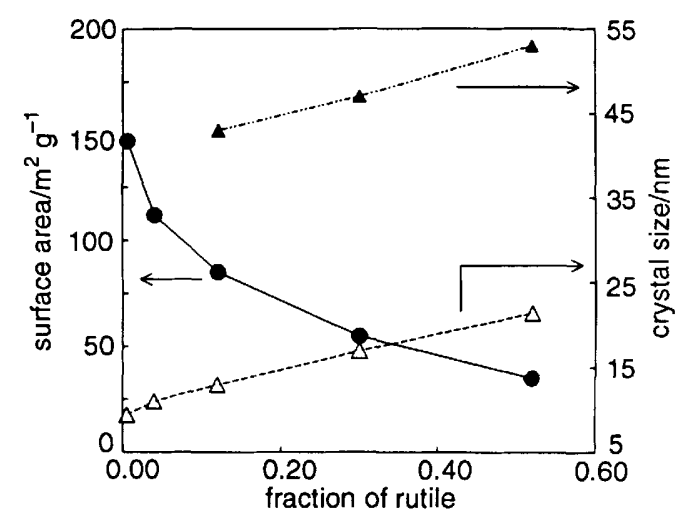

Fig. 12 Surface-area reduction and crystallite growth in unsupported titania membranes subjected to isothermal annealing at $390^{\circ} \mathrm{C}$. The crystallite sizes were calculated using eqn. (1). The points represent $5 \mathrm{~min}, 1 \mathrm{~h}, 8 \mathrm{~h}, 30 \mathrm{~h}$ and $100 \mathrm{~h}$ soaking times. $(\triangle)$ Anatase and (A) rutile. 
possible to make a rutile membrane, from an anatase precursor gel, which has a porosity detectable with the $\mathrm{N}_{2}$ adsorption technique. This means the complete densification was always associated with the complete conversion of the anatase phase into rutile. This observation prompted us to look into the relation between surface-area reduction (extent of sintering) and the extent of phase transformation. To get an idea of the difference in the extent of sintering in the anatase and rutile phases, two different geometrical surface areas were calculated. The geometrical surface area can be calculated, assuming the

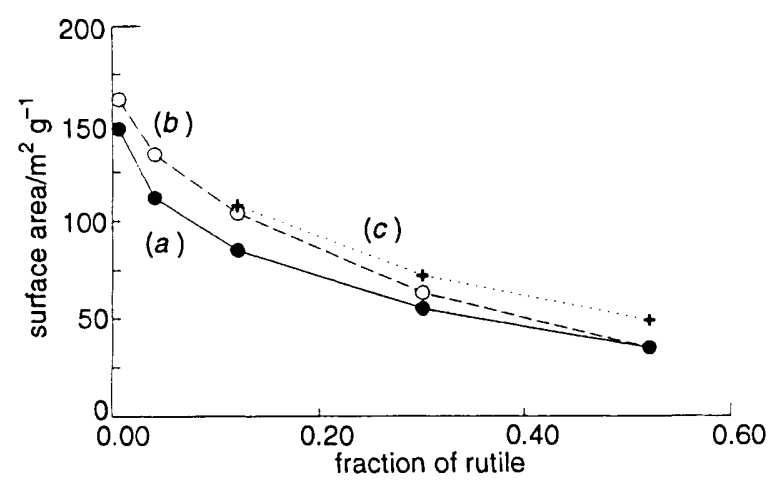

Fig. 13 Comparison of (a) BET surface area with two geometric surface areas, $(b)$ assuming only the anatase phase is contributing to the external surface and $(c)$ is taking both phases into account. The geometrical surface areas were calculated using eqn. (4) (a)

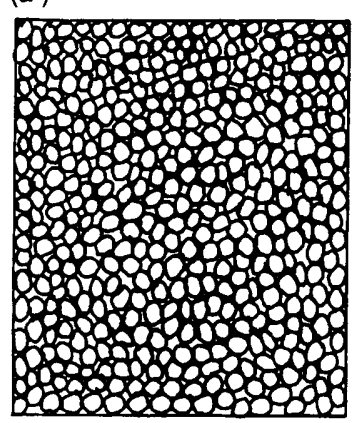

(b)

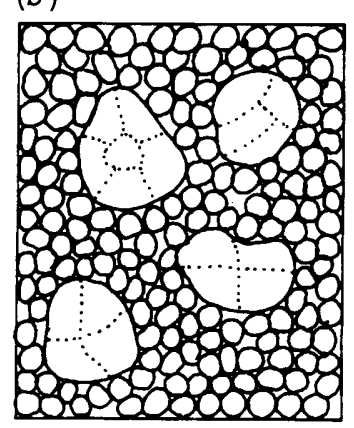

Fig. 14 Schematic representation of the nanostructural evolution of unsupported titania membranes, $(a)$ before transformation (only anatase) and (b) after partial transformation (both anatase and rutile) crystallites to be spherical, from the equation:

$$
\left.S_{\mathrm{GEO}}=3\left\{[1-f) / r_{\mathrm{A}} d_{\mathrm{A}}\right]+\left(f / r_{\mathrm{R}} d_{\mathrm{R}}\right)\right\}
$$

where $r$ is the radius of the crystallite calculated from XRD line broadening, $d$ is the density of the membrane and $f$ is the fraction of rutile present in the membrane. The subscripts A and $\mathbf{R}$ represent anatase and rutile. $S_{\mathrm{GEO}}$ was calculated in two ways: first by assuming that only anatase contributes to the surface area [considering only the first term of eqn. (4)] and the second by assuming both phases contribute to the surface area. Fig. 13 gives a comparison between the geometrical surface area and the actual BET surface area. The difference between curves $(a)$ and $(b)$ decreases with time (rutile content) and curve $(c)$ goes in parallel with curve $(a)$, indicating the fact that the contribution of the rutile to the total surface area of the sample is much less than the contribution of the anatase phase. This indicates indirectly that the rutile phase may be more or less completely dense as soon as it is formed. Probably, this may be due to the fact that during transformation atoms are very mobile because of bond breakage thereby causing enhanced sintering near the transformation temperature, sometimes referred to as the Hedvall effect. ${ }^{37}$ This is an indication of the fact that the densification and grain growth of the rutile phase during the phase transformation may be an important cause of surface-area reduction.

The nanostructural evolution of titania membranes may be schematically represented as shown in Fig. 14(a) and $(b)$ Fig. 14(a) represents the situation before phase transformation has started and $(b)$ represents the situation after partial transformation. The large areas represent the densified rutile regions, which are indicated to be polycrystalline. High resolution scanning electron micrographs (magnification of 200000 ) of titania membranes heated at 300 and $450{ }^{\circ} \mathrm{C}$ are given in Fig. 15. The sample heated at $300{ }^{\circ} \mathrm{C}$, contains only anatase as seen from the X-ray spectra given in Fig. 5, and a uniform distribution of pores, with crystallites of $c a .10-12 \mathrm{~nm}$. In Fig. $15(b)$ we clearly see smaller anatase crystallites and densified rutile regions, in agreement with the qualitative representation given in Fig. 14(b).

\section{Lanthana-doped Titania}

The results and discussions presented above suggest that the major causes of surface area and porosity reduction are anatase grain growth by surface diffusion and the enhanced (a)

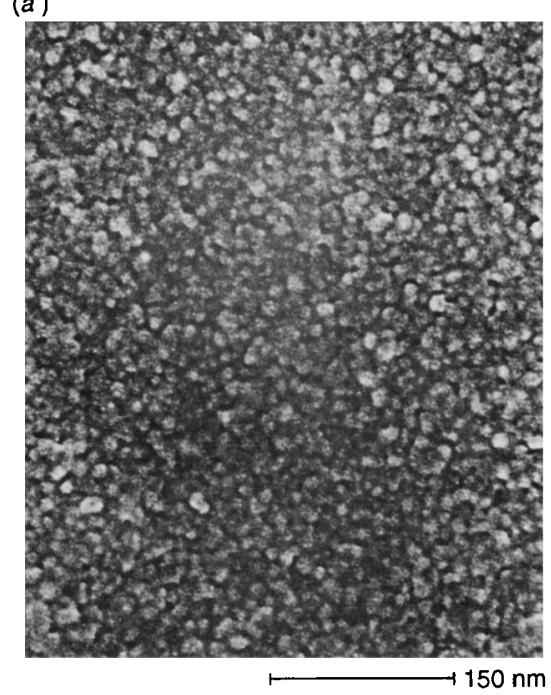

(b)

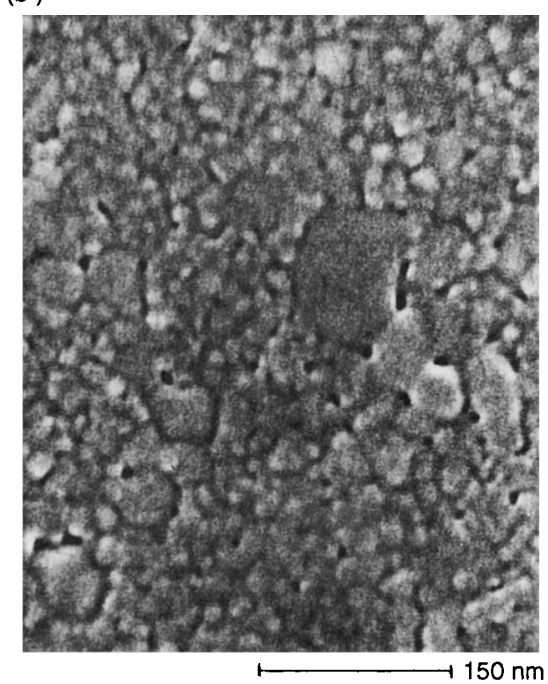

Fig. 15 FE-SEM pictures of the unsupported titania membranes heated at (a) 300 and $(b) 450{ }^{\circ} \mathrm{C}$ 
sintering during the phase transformation. It is known from the literature ${ }^{28}$ that rare-earth oxides increase the anatase-torutile transformation temperature. It is also known that the extent of this is of the same order of magnitude for all the rare-earth oxides studied. In this study we have selected lanthanum oxide for shifting the transformation temperature. The specific reason for selecting lanthanum oxide was that lanthanum has the highest ionic radius $\left(\mathrm{La}^{3+}, 1.061 \AA\right.$ ). The bigger the size of the dopant cation the more may be the tendency to segregate at the surface and thus retard the surface diffusion.

Lanthana-doped titania $\left(\mathrm{Ti}_{0.925} \mathrm{La}_{0.075} \mathrm{O}_{2}\right)$ is prepared by adding lanthanum nitrate solution to the peptized titania sol as shown in Fig. 1. Fig. 16 shows X-ray spectra of lanthanadoped membranes heated at different temperatures for $8 \mathrm{~h}$. All the peaks can be indexed as anatase and are very broad with a halfwidth in the range $1-0.68^{\circ}(2 \theta)$. No peak shift is observed up to $450{ }^{\circ} \mathrm{C}$. For $600{ }^{\circ} \mathrm{C}$ and higher temperatures, we clearly see a slight peak shift towards the lower $2 \theta$ side indicating an increase in the lattice parameter. This may be due to the dissolution of $\mathrm{La}^{3+}$ ions into the lattice of the titania. Even at $700{ }^{\circ} \mathrm{C}$ no trace of rutile could be detected. Lanthana addition has completely stabilized the anatase up to $700{ }^{\circ} \mathrm{C}$ for a soaking time of $8 \mathrm{~h}$. It was found that when these membranes are heated at $1000^{\circ} \mathrm{C}$ for $8 \mathrm{~h}$ the anatase converts completely to rutile. Fig. 17 gives the surface area and pore diameters of lanthana-doped membranes heat-

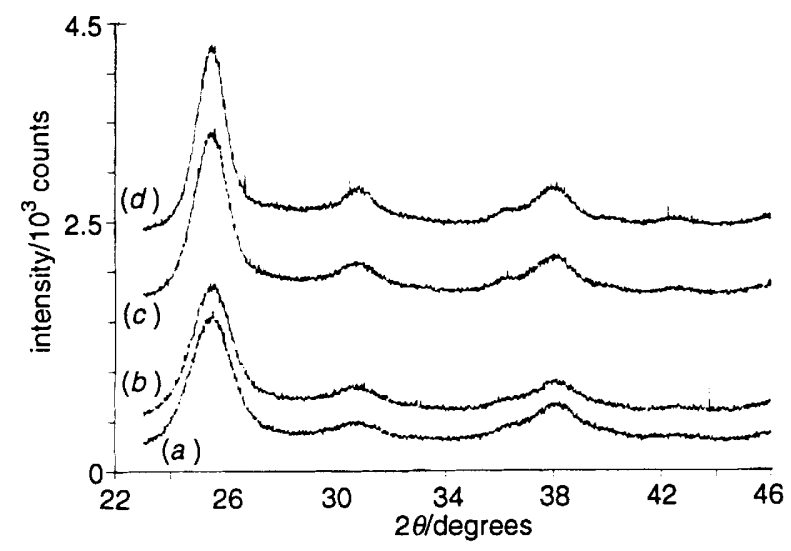

Fig. $16 \mathrm{X}$-Ray diffraction spectrum of unsupported lanthana-doped titania membranes heated at $(a) 300,(b) 450,(c) 600$ and $(d) 700{ }^{\circ} \mathrm{C}$ for $8 \mathrm{~h}$

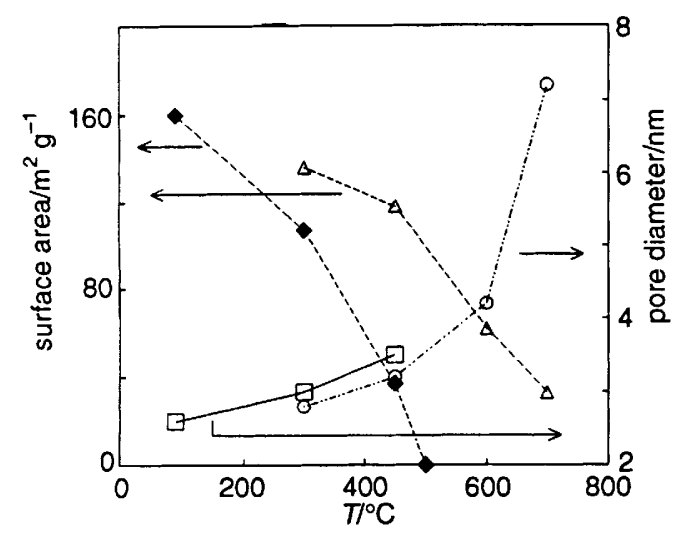

Fig. 17 Surface area and pore-size reduction in undoped and lanthana-doped unsupported membranes heated at different temperatures. (a) Surface area of undoped titania $(\diamond),(b)$ pore diameter of undoped titania ( $\square$ ), (c) surface area of lanthana-doped titania $(\triangle)$, and $(d)$ pore diameter of lanthana-doped titania $(O)$. Soaking time was $8 \mathrm{~h}$ treated at different temperatures for $8 \mathrm{~h}$. Values of undoped membranes are included for comparison. The differences in pore diameters of undoped and lanthana-doped membranes are very small. This means that the extent of pore growth in the anatase phase of both undoped and lanthana-doped membranes may not be much different. The difference in surface area increases with increasing calcination temperature, because in the case of undoped membranes rutile starts to appear at $350{ }^{\circ} \mathrm{C}$ and the surface area decreases drastically with increasing rutile content (see also Fig. 12). Lanthanadoped, non-supported membranes had a porosity of $c a .28 \%$ even after calcination at $700{ }^{\circ} \mathrm{C}$ for $8 \mathrm{~h}$.

\section{Conclusions}

(i) As-prepared titania membrane precursor xerogel layers, made by the hydrolysis of titanium isopropoxide, consist of anatase crystals. (ii) Undoped titania membranes had a surface area of $c a .165 \mathrm{~m}^{2} \mathrm{~g}^{-1}$ in the gel state which was reduced to zero after heat treatment at $600{ }^{\circ} \mathrm{C}$ for $8 \mathrm{~h}$. (iii) Isothermal Avrami analysis of the anatase-to-rutile transformation in undoped titania suggests that the transformation is initiated at dislocations or defects. The Avrami activation energy for the transformation was found to be $147 \mathrm{~kJ} \mathrm{~mol}^{-1}$. (iv) The surface area and porosity reduction of the unsupported titania membranes are caused by the anatase crystallite growth and the enhanced sintering of the rutile phase during transformation. (v) Lanthana-doped membranes had surface area, pore diameter and porosity of $c a .35 \mathrm{~m}^{2} \mathrm{~g}^{-1}, 7 \mathrm{~nm}$ and $28 \%$ after heat treatment at $700{ }^{\circ} \mathrm{C}$ for $8 \mathrm{~h}$, whereas undoped titania lost all measurable surface area after heat treatment at $600{ }^{\circ} \mathrm{C}$ for $8 \mathrm{~h}$.

\section{References}

1 J. Charpin, A. J. Burggraaf and L. Cot, Ind. Ceram., 1991, 11, 84.

2 V. T. Zaspalis, W. van Praag, K. Keizer, J. R. H. Ross and A. J. Burggraaf, J. Mater. Sci., 1992, 27, 1023.

3 A. Larbot, J-P. Fabre, C. Guizard and L. Cot, J. Am. Ceram. Soc., $1989,72,257$.

4 R. J. R. Uhlhorn, M. H. B. J. Huis in't Veld, K. Keizer and A. J. Burggraaf, J. Mater. Sci., 1992, $27,527$.

5 K. Foger and J. R. Anderson, Appl. Catal., 1986, 23, 139.

6 K. P. Kumar, K. Keizer, A. J. Burggraaf, T. Okubo, H. Nagamoto and S. Morooka, Nature (London), 1992, 358, 48.

7 E. F. Heald and C. W. Weiss, Am. Mineral., 1972, 57, 10.

8 F. C. Kracek, U.S. Geol. Surv., 1963, 1144-D, 81.

9 R. D. Shannon and J. A. Pask, J. Am. Ceram. Soc., 1965, 48, 391.

10 A. I. Sheinkman, V. A. Tyumentsev and A. A. Fotiev, Izv. Akad. Nauk SSSR, Neorg. Mater., 1984, 20, 1692.

11 U. Balachandran and N. G. Eror, J. Solid State Chem., 1982, 42, 276.

12 Y. Iida and S. Ozaki, J. Am. Ceram. Soc., 1961, 44, 120.

13 H. Knoll and U. Kühnhold, Naturwissenschaften, 1957, 44, 394.

14 A. W. Czanderna, C. N. R. Rao and J. M. Honing, Trans. Faraday Soc., 1958, 54, 1069.

15 C. N. R. Rao, Can. J. Chem., 1961, 39, 498.

16 F. Dachille, P. Y. Simens and R. Roy, Am. Mineral., 1968, 53, 1929.

17 A. Matthews, Am. Mineral., 1976, 61, 419.

18 R. D. Shannon, J. Appl. Phys., 1964, 35, 3414

19 J. Livage, personal communication, 1989.

20 F. Ikazaki, K. Uchida, A. Goto, M. Kawamura and S. Fujiwara, Funtai Kogaku Kaishi, 1983, 20, 717.

21 B. E. Yoldas, J. Mater. Sci., 1986, 21, 1087.

22 W. N. Schreiner and R. Jenkins, Adv. $X$-ray Anal., 1983, 26, 141.

23 D. W. Marquardt, J. Soc. Ind. Appl. Math., 1963, 11, 431.

24 H. P. Klug and L. E. Alexander, X-Ray Diffraction Procedures, Wiley, New York, 1974, p. 635.

25 R. A. Spurr and H. Myers, Anal. Chem., 1957, 29, 760.

26 K. P. Kumar, Ph.D. Thesis, Faculty of Chemical Technology, University of Twente, 7500 AE Enschede, The Netherlands, 1993. 
27 J. W. Christian, The Theory of Transformations in Metals and Alloys: Part I, Pergamon Press, Oxford, 1975.

28 S. Hishita, K. Koumoto and H. Yanagida, Ceram. Int., 1983, 9, 2.

29 M. Ocana, J. V. Garcia-Ramos and C. J. Serna, J. Am. Ceram. Soc., 1992, 75, 2010.

30 S. J. Gregg and K. S. W. Sing, Adsorption, Surface Area and Porosity, 2nd edn., Academic Press, London, 1982.

31 K. S. W. Sing, D. H. Everett, R. A. W. Haul, L. Moscou, R. A. Pierotti, J. Rouquerol and T. Siemieniewska, Pure Appl. Chem., 1985, 57, 603.

32 J. H. de Boer, in The Structure and Properties of Porous Materials, ed. D. H. Everett and F. S. Stone, Butterworth, London, 1958, p. 68 .
33 B. Abeles, L. F. Chen, J. W. Johnson and J. M. Drake, Isr. J. Chem., 1991, 31, 123.

34 J. L. Hebrard, P. Nortier, M. Pijolat and M. Soustelle, J. Am. Ceram. Soc., 1990, 73, 79.

35 M. Pijolat, M. Dauzat and M. Soustelle, Solid State Ionics, 1992 50, 31 .

36 Thermochemical Data of Pure Substances: Part II, ed. Ihsan Barin, VCH, Weinheim, 1989, p. 1547.

37 W. D. Kingery, H. K. Bowen and D. R. Uhlmann, Introduction to Ceramics, Wiley, New York, 2nd edn., 1976, p. 425.

Paper 3/03229I; Received 7th June, 1993 